\title{
Frequency-based control of islanded microgrid with renewable energy sources and energy storage
}

\author{
Konstantinos O. OUREILIDIS ${ }^{1}$, Emmanouil A. BAKIRTZIS ${ }^{1}$, \\ Charis S. DEMOULIAS ${ }^{1}$
}

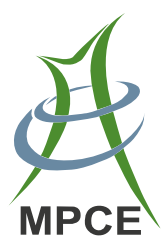

\begin{abstract}
When a microgrid is mainly supplied by renewable energy sources (RESs), the frequency deviations may deteriorate significantly the power quality delivered to the loads. This paper proposes a frequency-based control strategy, ensuring the frequency among the strict limits imposed by the Standard EN 50160. The frequency of the microgrid common AC bus is determined by the energy storage converter, implementing a proposed droop curve among the state of charge (SoC) of the battery and the frequency. Therefore, the information of the SoC becomes known to every distributed energy resource (DER) of the microgrid and determines the active power injection of the converter-interfaced DERs. The active power injection of the rotating generators remains unaffected, while any mismatch among the power generation and consumption is absorbed by the energy storage system. Finally, in case of a solid short-circuit within the microgrid, the energy storage system detects the severe voltage decrease and injects a large current in order to clear the fault by activating the protection device closer to the fault. The proposed control methodology is applied in a microgrid with PVs, wind
\end{abstract}

CrossCheck date: 15 October 2015

Received: 12 March 2015 / Accepted: 28 September 2015/Published online: 16 January 2016

(C) The Author(s) 2016. This article is published with open access at Springerlink.com

$\bowtie$ Konstantinos O. OUREILIDIS

oureili@yahoo.gr

Emmanouil A. BAKIRTZIS

emmpakir@auth.gr

Charis S. DEMOULIAS

chdimoul@auth.gr

1 Department of Electrical and Computer Engineering, Aristotle University of Thessaloniki, Thessaloniki 54124, Greece generators and a battery, while its effectiveness is evaluated by detailed simulation tests.

Keywords Microgrid, Frequency control, Renewable energy sources, Energy storage system, SoC control

\section{Introduction}

As renewable energy sources (RESs) integration has considerably increased, the microgrid concept has been developed. According to the U.S. Department of Energy (DOE) [1], a microgrid is defined as a cluster of DERs and local loads connected to the utility grid, which can operate in parallel to the grid or isolated as an island. The microgrid concept also includes the integration and control of storage assets in order to ensure a high power quality $[2,3]$.

In the literature, the critical role of the energy storage system is focused on the regulation of the voltage and frequency [4] and on preserving the power balance due to the intermittent operation of the RESs [3, 4]. Furthermore, other ancillary functions of the energy storage may include the low-voltage ride-through (LVRT) capability, load leveling, peak shaving and operating reserve $[3,5]$. When the microgrid is comprised of RESs and energy storage systems in island operation mode, the energy storage usually acts as grid-forming source and regulates the common AC bus appropriately, while the RESs are controlled to inject the available power to the microgrid [6]. However, this approach may lead the SoC to unsafe operation, provoking a damage in the energy storage. Furthermore, an active power imbalance among the generation and the consumption may deteriorate the microgrid frequency regulation [7]. Therefore, the control strategy should take into account the $\mathrm{SoC}$ control, ensuring a prolonged lifetime for the battery. 
Since in island operation mode, the frequency is no longer imposed by the utility grid, several control strategies propose the implementation of a secondary control for frequency regulation in order to ensure a frequency within a stipulated band [8]. This supervisory control level can be implemented either in a centralized or decentralized way $[9,10]$. In case of implementing a centralized control method, a microgrid central controller (MCC) modifies the control of the DERs appropriately, by gathering measurements from local controllers [10]. In this control approach, the communication is considered necessary. However, the system reliability is reduced, since it is dependent on the operation of a physical communication system. On the other hand, the decentralized approach aims at providing the highest possible autonomy [11, 12]. Nevertheless, in many cases the communication is still considered a basic principle of the control.

In $[13,14]$, frequency is used as a communication agent for the energy control in an islanded microgrid, with no need of further communication. The goal focuses on the adjustment of the conventional droop method, considering the frequency variation and the $\mathrm{SoC}$ of the energy storage. In [15], a decentralized energy management integrated in a microgrid with PVs and batteries is examined. The SoC of the battery determines the microgrid frequency, nevertheless additional control schemes are needed to achieve coordination with other kind of DERs. In [16], the frequency is also used as a communication parameter of the $\mathrm{SoC}$ of the energy storage system in a microgrid with converter-interfaced DERs. However, all the connected sources are considered as converter-interfaced DERs, while, due to the presence of secondary control and the associated communication network, only a limited frequency deviation is used in the control strategy implementation. Moreover, in [16], no fault-clearance methods are examined, and no voltage regulation is investigated. A power control strategy focusing on the control of the SoC of the energy storage is also proposed in [17]. The frequency is used again as a communication signal for sending the information of charging/discharging to all DERs. However, only converter-interfaced generation units are considered.

This paper investigates the case of a microgrid in a small Greek island, which is currently supplied by conventional power sources. The conventional power sources are synchronous generators, driven by diesel engines; three generators, each one rated at $220 \mathrm{kVA}, 400 \mathrm{~V}, 50 \mathrm{~Hz}$ and one generator rated at $90 \mathrm{kVA}, 400 \mathrm{~V}, 50 \mathrm{~Hz}$. The loads are concentrated, representing the small town consumption. According to measurements, the peak load is $350 \mathrm{~kW}$ (15min average power) during summer period, while it is reduced to $70 \mathrm{~kW}$ during the winter. The annual energy consumption corresponds to $1020 \mathrm{MWh}$.
Since the most abundant RESs in Greece are wind and solar power, this case study proposes the replacement of the conventional diesel-driven generators with a microgrid consisting of a $230 \mathrm{kWp}$ PV installation and two asynchronous wind generators (WGs) of $275 \mathrm{~kW}$ each one. The energy production of the RESs cover in average $90 \%$ of the total load energy consumption. Taking into account a projected $50 \%$ increase of the load demand, the total annual energy consumption yields $1530 \mathrm{MWh}$. The WGs cover approximately $80 \%$ of the projected annual energy consumption (1224 MWh), while the rest $20 \%$ (306 MWh) is covered by the PVs.

In order to maintain the power balance in the microgrid, a battery of $7.3 \mathrm{MWh}$ is also added. The battery bank is selected to provide one day autonomy in the month with the peak demand, which equals to $4 \mathrm{MWh}$, representing a typical day in August. The permissible depth of discharge (DOD) is assumed $60 \%$, while the converter efficiency is considered equal to $95 \%$. In order to protect the microgrid from faults, the battery converter is sized to inject 1.5 p.u. of its nominal current for $2 \mathrm{~s}$ (at $400 \mathrm{~V}$ level), i.e. $1500 \mathrm{~A}$ in the microgrid under study. Thus, the apparent power of the battery converter is $850 \mathrm{kVA}$ at $400 \mathrm{~V}$ rated voltage. The microgrid under study is presented in Fig. 1.

In order to ensure power balance among the power production and consumption without implementing any physical communication between the DERs in this small Greek island, this paper proposes a decentralized control strategy based only on local measurements for the effective

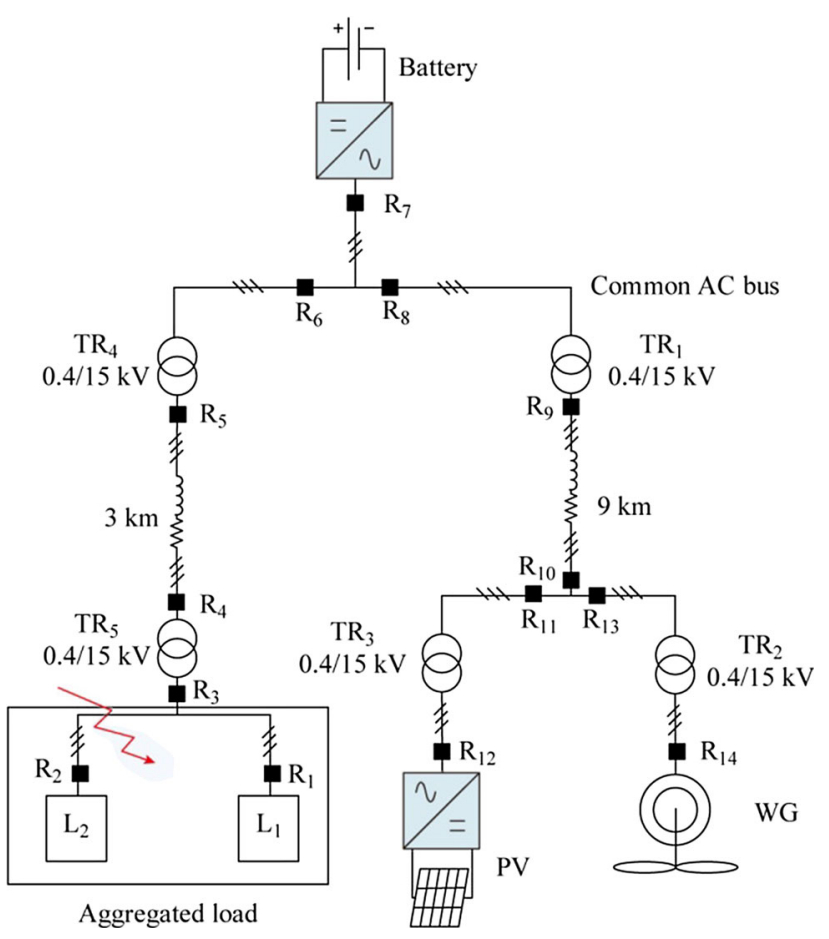

Fig. 1 Single-line microgrid scheme 
frequency control in a microgrid with an energy storage system. The energy storage is considered as the converterinterfaced battery. According to the proposed methodology, the battery converter adjusts the microgrid frequency by considering its $\mathrm{SoC}$ and implementing a proposed droop curve. Thus, the information of the $\mathrm{SoC}$ is transferred indirectly through the frequency to all DERs, which determine their power output appropriately. In this way, the frequency always remains within the preassigned limits, while the SoC control ensures a prolonged battery lifetime. Finally, the case of a short-circuit is examined. The battery converter identifies the fault due to the deep voltage decrease and modifies its control in order to inject a large current. The fault is cleared within a few seconds.

The paper is organized as follows: Section 2 describes the microgrid modelling. Extended simulation results are demonstrated and discussed in Section 3. Finally, the control strategy advantages are concluded in Section 4.

\section{System description and modelling}

\subsection{Battery energy storage system model}

The battery bank consists of three parallel battery strings, each string composed by 450 OPzS-type lead-acid batteries of $2 \mathrm{~V}, 2700 \mathrm{MWh}$ connected in series. The battery bank is modelled as a variable DC voltage source in series with an internal resistance [18]. The internal battery resistance depends on the $\mathrm{SoC}$ and temperature, while its value differs between charging and discharging periods. However, since the proposed control method presents small sensitivity to the variations of the battery terminal voltage, the internal resistance is considered constant $(20 \mathrm{~m} \Omega)$. The open-circuit voltage of a $2 \mathrm{~V}$ battery depends on the SoC of the battery according to the following polynomial equation:

$V_{\mathrm{oc}}=a+b \cdot S o C+c \cdot S o C^{2}+d \cdot S o C^{3}$

where $V_{\mathrm{oc}}$ represents the open-circuit voltage, and the parameters are equal to: $a=1.958, b=1.155 \times 10^{-3}$,

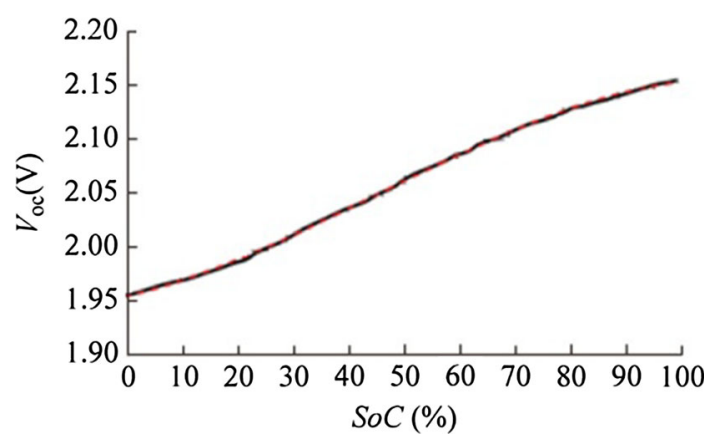

Fig. 2 Open-circuit voltage $V_{\mathrm{oc}}-\mathrm{SoC}$ characteristic of a $2 \mathrm{~V}$ battery cell $c=2.946 \times 10^{-5}, d=-2.112 \times 10^{-7}$. The open-circuit voltage are equation is illustrated in Fig. 2 , given by the battery manufacturer [19]. In order to filter the high order harmonics and decrease the DC current ripple at $20 \%$ of the nominal current, an LC filter with parameters $L=1$ $\mathrm{mH}$ and $C=100 \mu \mathrm{F}$ is placed on the output of the battery bank. The SoC of the battery is calculated by measuring the current injection from the battery and taking the initial electrical charge of the battery into account:

$S o C(t)=\frac{Q_{0}-\int_{t_{0}}^{t} I_{\text {bat }}}{Q_{\text {bat }}}$

where $Q_{0}$ is the battery charge at $t=t_{0}, Q_{\text {bat }}$ is the nominal battery charge and $I_{\text {bat }}$ the battery current.

The bidirectional DC/AC three-phase converter is placed at the output of the filter. This converter is formed by a sinusoidal pulse width modulation (SPWM) and its purpose in steady-state mode is to control the magnitude and frequency of the AC bus, according to the proposed control strategy. For this reason, it can be characterized as a grid-forming converter [20]. Furthermore, taking measurements from the battery bank about its SoC, the converter undertakes the charge and discharge operation of the battery.

The control strategy is based on forming an AC microgrid with frequency proportional to the $\mathrm{SoC}$ of the battery. Therefore, each DER measures the SoC of the battery indirectly, by measuring the frequency at their nodes. By implementing the proposed control strategy, no further communication signal is needed to be transferred, while the frequency of the main bus remains within the preassigned limits imposed by [8] for islanded grids.

The proposed droop curve is shown in Fig. 3. When the SoC of the battery equals to $40 \%(\mathrm{DOD}=60 \%)$, the battery is considered empty and the frequency takes the minimum permissible value, i.e. $49 \mathrm{~Hz}$. When the $\mathrm{SoC}$ is equal to $100 \%$ and the battery is fully charged, the

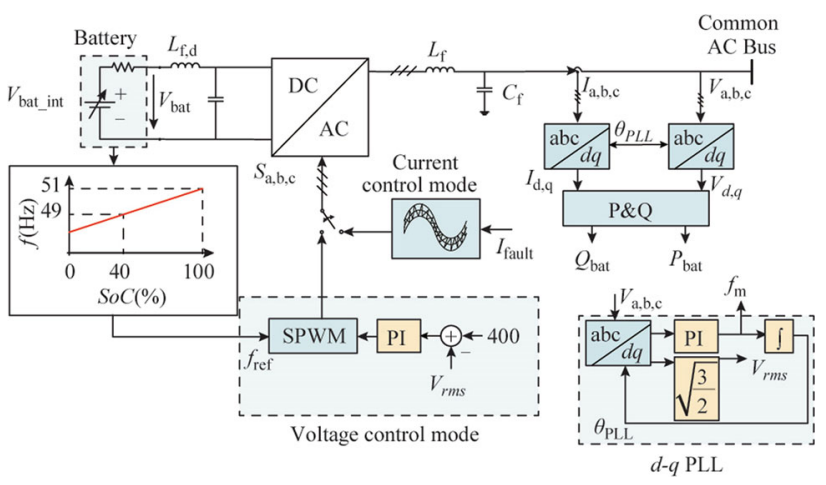

Fig. 3 Battery storage system control scheme 
frequency corresponds to the maximum permissible value, i.e. $51 \mathrm{~Hz}$. The mathematical equation can be expressed as:

$f_{\mathrm{ref}}=f_{\min }+m_{1} \cdot\left(S o C-S o C_{\min }\right)$

$m_{1}=\frac{f_{\max }-f_{\min }}{S o C_{\max }-S o C_{\min }}$

where $f_{\text {ref }}$ is the reference frequency, $f_{\max }=51 \mathrm{~Hz}$, $f_{\min }=49 \mathrm{~Hz}, S o C_{\max }=100 \%$ and $S o C_{\min }=40 \%$.

The internal control of the converter is also presented in Fig. 3. In order to maintain the line voltage of the AC bus at $400 V_{\text {rms }}$ independently of the active and reactive power deviations among the DERs and the loads, a feedback control compares the magnitude of the measured voltage with the desired of $400 \mathrm{~V}$. Since the nominal open-circuit voltage of the discharged battery is sufficiently high, the converter operates constantly at the linear region.

By implementing the proposed control strategy, the converter operates at four quadrants, allowing the charging and discharging of the battery bank. Finally, the converter absorbs or injects the appropriate amount of reactive power to maintain the voltage at $400 \mathrm{~V}$.

\subsection{PV system model}

The PV installation consists of $920 \mathrm{PV}$ panels of $250 \mathrm{Wp}$ each, forming a DC voltage equal to $700 \mathrm{~V}$. The PV model is developed in PSIM environment [21] and the corresponding parameters appear in [22]. A DC/AC converter is used in order to inject the reference value of the active and reactive power. The active power is equal to the minimum among the following calculations: (1) the active power determined by the maximum power point tracker (MPPT) and (2) the active power resulted by the proposed active power -frequency characteristic, which is presented in Fig. 4. According to this characteristic, the active power injection ceases when the microgrid frequency reaches the maximum value of $51 \mathrm{~Hz}$. This situation refers to the case of a fully-charged battery, where there is no need for power from the PVs. The implemented control strategy proposes

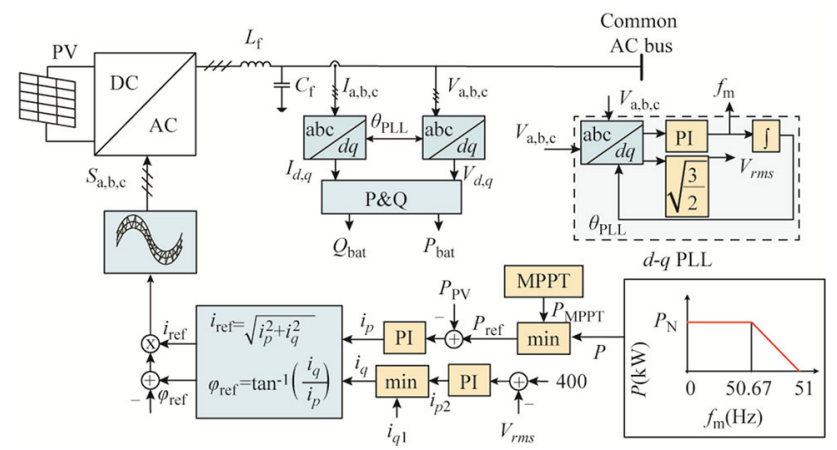

Fig. 4 PV control scheme the linear deterioration of the active power injection, when the system frequency decreases from $51 \mathrm{~Hz}$ to $50.67 \mathrm{~Hz}$, i.e. from the fully-charged situation of $\mathrm{SoC}=100 \%$ to almost fully-charged of $\mathrm{SoC}=90 \%$ :

$P_{\mathrm{PV}}=P_{\mathrm{MMPT}} \quad$ for $\quad f_{\mathrm{m}} \leq 50.67 \mathrm{~Hz}$

$P_{\mathrm{PV}}=P_{\mathrm{MPPT}}-m_{2} \cdot\left(f_{\mathrm{m}}-50.67\right) \quad$ for $f_{\mathrm{m}} \geq 50.67 \mathrm{~Hz}$

$m_{2}=\frac{P_{\mathrm{MPPT}}}{f_{\max }-50.67}$

where $f_{\mathrm{m}}$ is the microgrid frequency, as it is measured by the phase locked loop (PLL).

Therefore, the converter calculates the active power from the measured voltage and current components at the output filter and compares with the injected active power. The error signal is driven to a PI controller in order to determine the active power current component, $i_{\mathrm{p}}$. The deterioration of the injected power is implemented by shifting away from its MPP.

The reactive power is determined by comparing the reactive power current capability of the converter, $i_{\mathrm{q} 1}$, with $i_{\mathrm{q} 2}$, which corresponds to the appropriate amount of reactive power in order to keep the voltage at the terminals of the converter at $400 \mathrm{~V}$ :

$i_{q}=\min \left\{i_{q 1}, i_{q 2}\right\}$

$i_{q 1}=\sqrt{I_{N}^{2}-i_{p}^{2}}$

where $I_{\mathrm{N}}$ is the nominal current of the converter.

The PV converter can be considered as grid-supplier converter, which injects the reference active and reactive power. The reference output current is formed by the active and reactive power components $i_{p}$ and $i_{q}$, respectively. This current is used in a hysteresis current band of $1 \%$ width, in order to form the SPWM. The control scheme of the PV converter is presented in Fig. 4. The amplitude of the current $i_{\text {ref }}$ is formed by the currents $i_{p}$ and $i_{q}$, while the angle from the PLL angle $\theta_{\mathrm{PLL}}$ and the reference angle $\varphi_{\text {ref }}$ as follows:

$i_{\text {ref }}=\sqrt{i_{p}^{2}+i_{q}^{2}}$

$\varphi_{\text {ref }}=\tan ^{-1}\left(\frac{i_{q}}{i_{p}}\right)-\theta_{\mathrm{PLL}}$

\subsection{Wind generators}

The wind generators are modelled as squirrel cage asynchronous machines with parameters as appear in Table 1. The generators are directly coupled to the microgrid, operating as constant-speed wind generators, without needing any further control or any converter, as shown in Fig. 5. The active power output depends on the 
Table 1 WG parameters

\begin{tabular}{ll}
\hline Parameters & $\mathrm{WG}_{1}, \mathrm{WG}_{2}$ \\
\hline Rated power & $275 \mathrm{~kW}$ \\
Rated voltage & $400 \mathrm{~V}$ \\
Number of poles & 6 \\
Moment of inertia & $230 \mathrm{~kg} \cdot \mathrm{m}^{2}$ \\
\hline
\end{tabular}

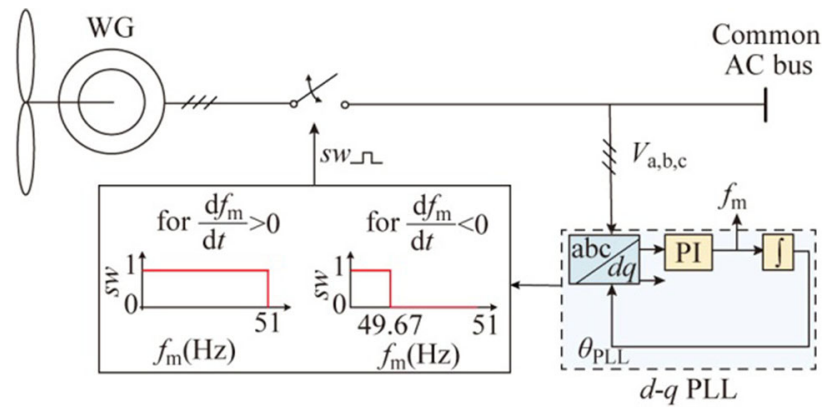

Fig. 5 WG control scheme

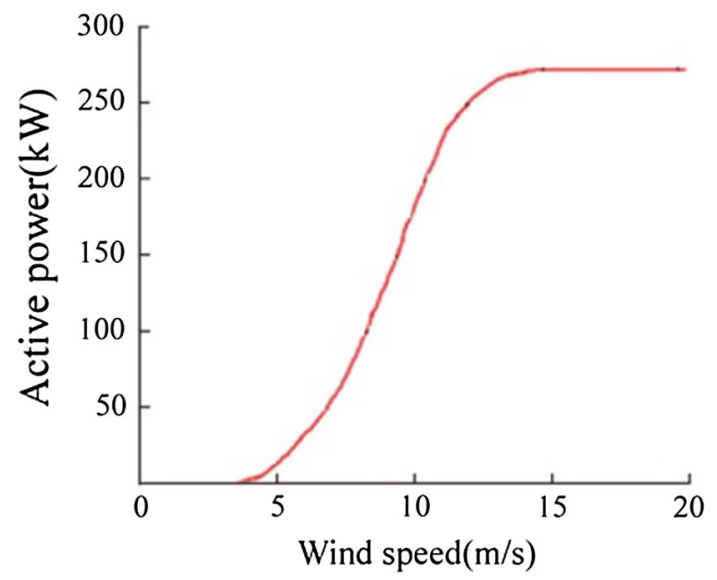

Fig. 6 Wind speed-active power characteristic of a $275 \mathrm{~kW}$ WG

wind velocity, as it is presented in Fig. 6. When the wind speed varies among $3 \mathrm{~m} / \mathrm{s}$ and $13 \mathrm{~m} / \mathrm{s}$, the WG follows the wind power, while for higher wind speed up to $20 \mathrm{~m} / \mathrm{s}$, it operates as constant power source by adjusting the mechanical torque. During the battery charge $\left(\mathrm{d} f_{\mathrm{m}} / \mathrm{d} t>0\right)$, the WGs are disconnected when the frequency reaches $51 \mathrm{~Hz}$. On the other hand, during the battery discharge $\left(\mathrm{d} f_{\mathrm{m}} / \mathrm{d} t<0\right)$, the WGs are reconnected when the frequency drops below a limit, in order to avoid a cycle of continuous connections and disconnections. This limit can be evaluated through long-time observations. In this paper, the frequency limit for reconnection is considered equal to $49.67 \mathrm{~Hz}$, i.e. $\mathrm{SoC}=60 \%$. The connections/disconnections of the WGs are performed by an over/underfrequency relay through the signal $s w$.
Table 2 Transformer 0.4/15 kV parameters [23]

\begin{tabular}{llll}
\hline Parameter & $\mathrm{TR}_{1}$ & $\mathrm{TR}_{2}, \mathrm{TR}_{4}$ & $\mathrm{TR}_{3}$ \\
\hline Rated power & $1000 \mathrm{kVA}$ & $800 \mathrm{kVA}$ & $400 \mathrm{kVA}$ \\
Impedance $u_{\mathrm{k}}$ & $6 \%$ & $5 \%$ & $4.5 \%$ \\
No-load loss & $1300 \mathrm{~W}$ & $1940 \mathrm{~W}$ & $5700 \mathrm{~W}$ \\
Load loss & $10200 \mathrm{~W}$ & $8200 \mathrm{~W}$ & $4100 \mathrm{~W}$ \\
\hline
\end{tabular}

\section{Simulation results}

The examined microgrid is depicted in Fig. 1. The load is considered as a concentrated three-phase symmetrical constant power load. The connection lines are of ACSR $35 \mathrm{~mm}^{2}$ type with resistance $R=0.576 \Omega$ and inductance $X=0.397 \Omega$. A $0.4 / 15 \mathrm{kV}$ transformer is connected at the output of the DERs and the load, with electrical parameters given in the Table 2.

Three different simulation cases are examined, by using PSIM software. For simulation purposes, the nominal battery electrical charge is considered equal to $8100 \mathrm{~A} \cdot \mathrm{s}$.

\subsection{Case 1: constant wind speed}

In the first case, the wind speed is considered constant and equal to $15 \mathrm{~m} / \mathrm{s}$. According to Fig. 6, each WG injects $275 \mathrm{~kW}$. The power from the MPP tracker of the PV offers $100 \mathrm{~kW}$. Therefore, the total available active power from the RESs is $650 \mathrm{~kW}$, while the aggregated load demands $400 \mathrm{~kW}$ with power factor $(p f)$ equal to 0.8 . Initially, at $t=1 \mathrm{~s}$, the $S o C$ of the battery equals to $98.8 \%$, therefore it charges until the fully-charged condition. The frequency of the common AC bus is set to $50.93 \mathrm{~Hz}$ by the battery converter. Since the frequency is higher than $50.67 \mathrm{~Hz}$, the PV converter injects active power by following the active power-frequency curve, as shown in Section 2.2. The simulation results are shown in Fig. 7.

When the $S o C$ of the battery reaches the value of $100 \%$ and frequency is set to $51 \mathrm{~Hz}$, at $t=1.5 \mathrm{~s}$, the over/under frequency relay of the wind generators (R14) is activated and disconnects them from the microgrid, resulting in a new power balance. The active power deficit is covered by the battery, which changes its operation mode to discharge mode. As a result, the frequency decreases linearly and the converter of the PV increases the injected active power. At $t=6.6 \mathrm{~s}$, the frequency becomes equal to $49.67 \mathrm{~Hz}$ (i.e. $S o C=60 \%$ ), and the wind generators reconnect to the microgrid, forming again a new combination of active power among the DERs. Since the microgrid load consumption can be fulfilled and there is a surplus of active power, the battery control changes to charging operation 


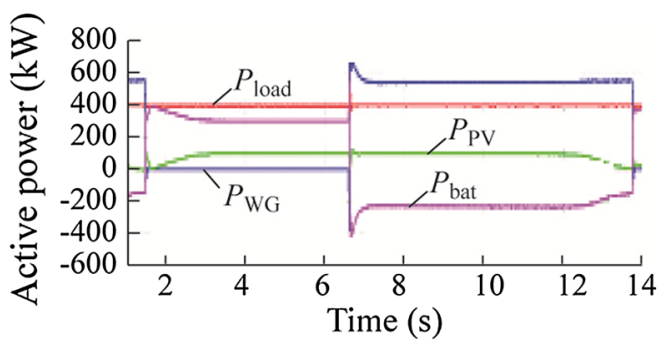

(a) Active power of the load, WG, PV and battery

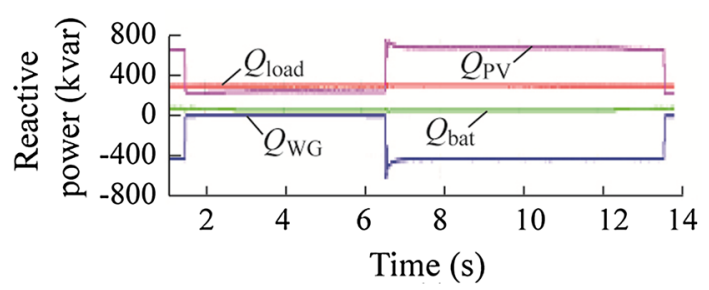

(b) Reactive power output of the load, WG, PV and battery

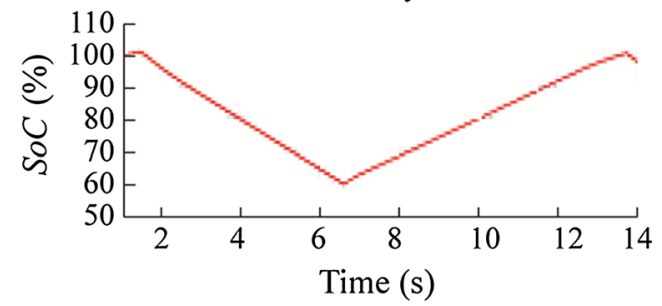

(c) Battery SoC

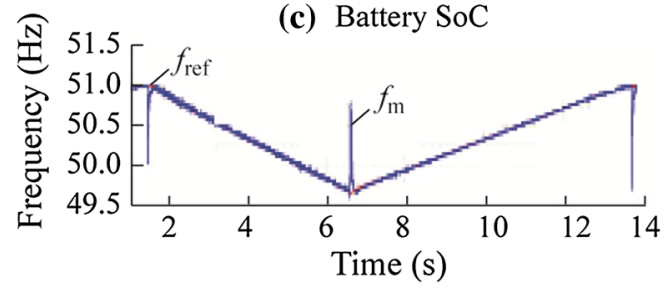

(d) Frequency reference fref and calculated by the PLL frequency $f_{\mathrm{m}}$

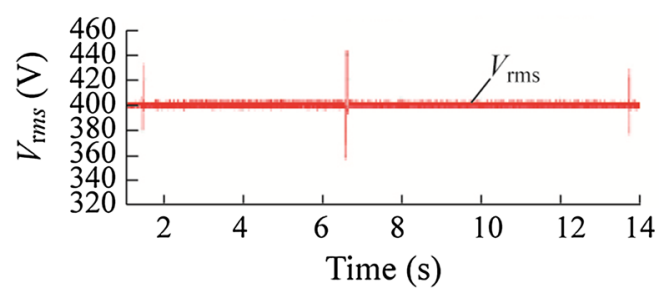

(e) rms voltage magnitude of the common AC bus

Fig. 7 Simulation results for case 1

mode, as is shown in Fig. 7. The $\mathrm{SoC}$ of the battery increases, causing a respective increase in the common frequency. When the frequency exceeds $50.67 \mathrm{~Hz}$, the PV converter decreases linearly its injected active power. When the frequency reaches $51 \mathrm{~Hz}$ (at $t=13.7 \mathrm{~s}$ ), the PV zeroes its output, while the WGs disconnect from the microgrid, in order to protect the battery from overcharging.
According to the presented simulation results, the proposed control strategy ensures that the frequency remains inside the strict limits of [8], meanwhile, the SoC of the battery is controlled effectively. Thus, the load is supplied with a high power quality.

\subsection{Case 2: variable wind speed}

The second simulation test deals with the effect of the wind speed variation. The load is still considered equal to $400 \mathrm{~kW}, p f=0.8$, while the PV MPPT $100 \mathrm{~kW}$. The battery $S o C$ equals to $49.7 \%$ forming an AC voltage of $49.32 \mathrm{~Hz}$ frequency. At $t=1 \mathrm{~s}$, the WGs operate at $8 \mathrm{~m} / \mathrm{s}$ and inject $300 \mathrm{~kW}$ active power to the microgrid. At $t=1.5 \mathrm{~s}$, a wind speed oscillation with magnitude equal to $4 \mathrm{~m} / \mathrm{s}$ and frequency of $1 \mathrm{~Hz}$ takes place. At this range of wind speed, the mechanical power of the WGs follows the wind power.

Assuming the rotational speed of the WG almost constant, the variation of the mechanical torque $T_{\text {mech }}$ can be given by the following equation:

$T_{\text {mech }}(\mathrm{kNm})=-2.86+1.43 \sin (2 \pi t)$

Due to the WG inertia, while the mechanical torque oscillates with an amplitude equal to $50 \%$ of its average speed, active power variation is restricted to $25 \%$ of its average power. The simulation results appear in Fig. 8. As is demonstrated, the wind speed variation is absorbed by the battery, causing a respective variation in the frequency of the AC bus. When the battery charges, the frequency increases, while the opposite effect takes place when the battery discharges. Since the frequency is always below $50.67 \mathrm{~Hz}$, the PV is not affected and contributes with $100 \mathrm{~kW}$. Despite of the large wind speed variation with the corresponding fluctuation in the reactive power of the WGs, the effect on the voltage of the common AC bus is seamless.

The simulation results presented in this case show that the proposed control strategy can absorb any large wind speed variations, while the frequency and the voltage still remains among the preassigned limits.

\subsection{Case 3: short-circuit at the load}

The final case examines a solid short-circuit at the load terminals. At $t=1 \mathrm{~s}$, the WGs contribute with $300 \mathrm{~kW}$ and the battery $\mathrm{SoC}$ equals to $49.4 \%$. As a result, the frequency of the common $\mathrm{AC}$ bus is set to $49.31 \mathrm{~Hz}$ and the PV injects the active power from the MPPT, which is equal to $100 \mathrm{~kW}$. Each load $\mathrm{L}_{1}$ and $\mathrm{L}_{2}$ absorbs $200 \mathrm{~kW}$, $p f=0.8$, therefore the battery does not inject any active power. At $t=1.5 \mathrm{~s}$, a short-circuit takes place at the terminals of the load $\mathrm{L}_{2}$, as it is shown in Fig. 1. When the 


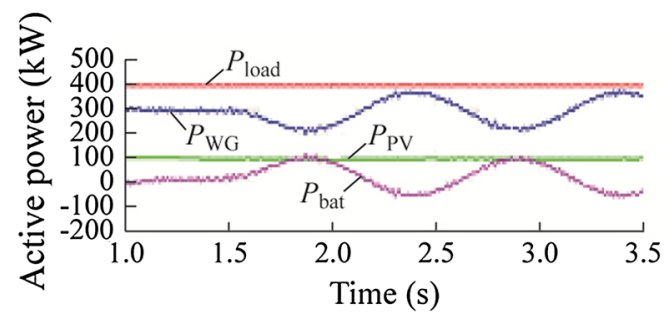

(a) Active power of the load, WG, PV and battery

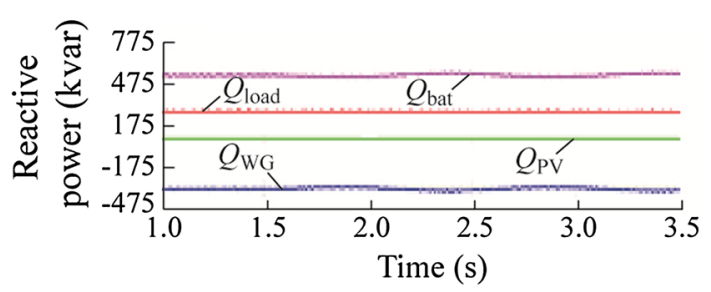

(b) Reactive power output of the load, WG, PV and battery

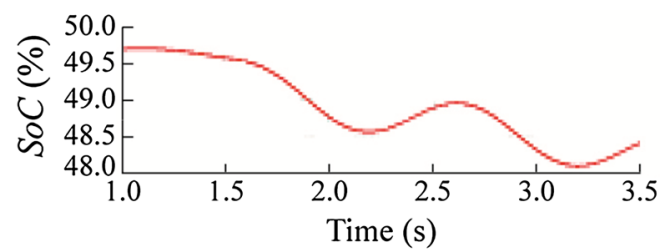

(c) Battery SoC

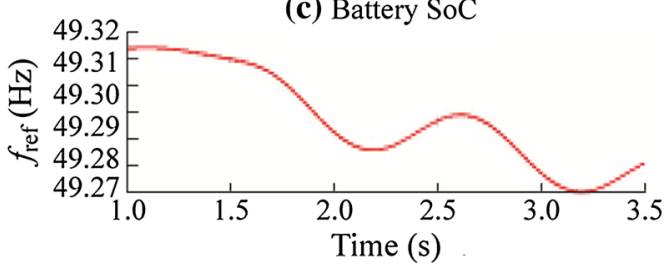

(d) Battery frequency reference

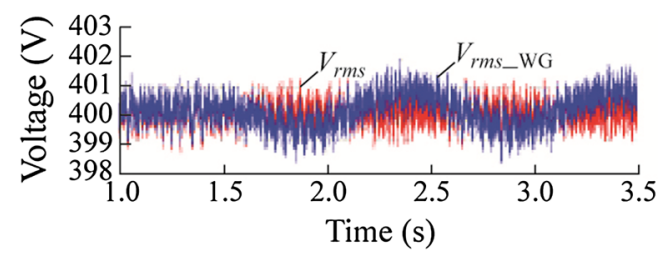

(e) rms voltage at the common $\mathrm{AC}$ bus (with red color) and at the terminals of the WGs (with blue color)

Fig. 8 Simulation results for case 2

voltage rms value drops below $300 \mathrm{~V}$ (as shown in Fig. 9), the battery converter senses the fault and adjusts the control to current-control mode in order to inject a current equal to $1500 \mathrm{~A}$ and clear the fault. As long as the voltage remains at very low values, the over/under voltage relays $R_{14}$ of the WGs and $R_{12}$ the PV respectively are activated disconnecting these DERs. As a result, only the battery feeds the fault with this large current, causing the respective activation of the protection device at $t=3.5 \mathrm{~s}$, i.e. $2 \mathrm{~s}$ after the short-circuit appearance.

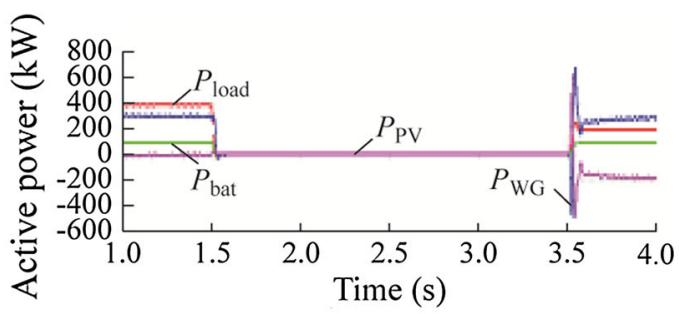

(a) Active power output of the load, WG, PV and battery

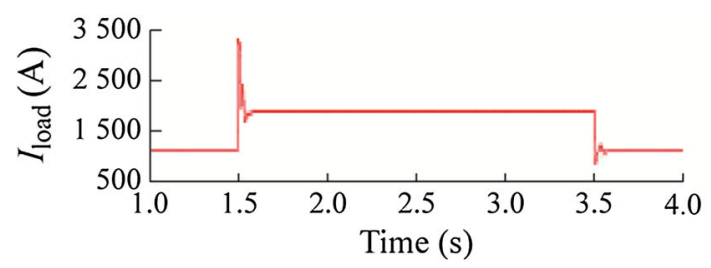

(b) rms load current

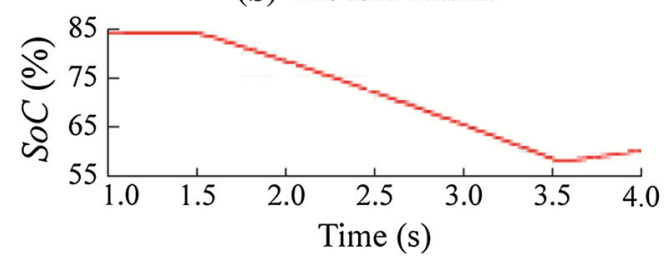

(c) Battery SoC

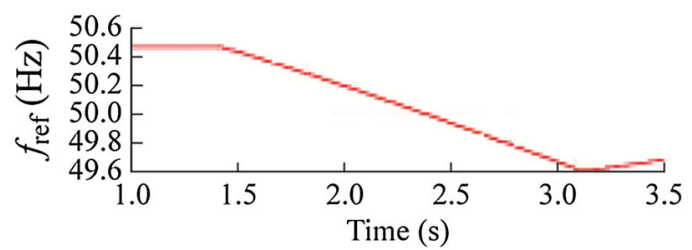

(d) Battery frequency reference

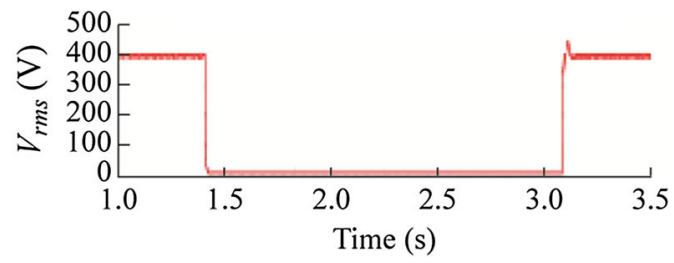

(e) rms voltage at the common $\mathrm{AC}$ bus

Fig. 9 Simulation results

Subsequently, the battery converter returns to voltagesource control mode and the RESs reconnect to the microgrid. The microgrid returns to steady-state operation after a small transient effect. Since $\mathrm{L}_{2}$ is disconnected from the microgrid, the aggregated load current becomes lower than in the pre-fault operation. As a result, the total active power balance has changed and the surplus of active power is absorbed by the battery. The simulation results are presented in Fig. 9, proving the effectiveness of the proposed control strategy. As is figured, the battery discharges during the fault and its corresponding SoC is decreasing. After the fault clearance, the battery switches to charge mode and its SoC is increasing. 


\section{Conclusion}

A new frequency-based control strategy for a microgrid with an energy storage is proposed. The frequency of the main AC bus is determined by the battery SoC in terms of implementing a proposed droop curve. The microgrid could consist of both converter-interfaced and rotating generators. In the examined microgrid, only RES have been considered, showing the effectiveness of the proposed methodology even under intermittency of the primary source. The aim of the proposed control strategy is to ensure a frequency deviation among the strict limits of the Standard EN 50160 for providing a high quality power to the connected loads. At the same time, the battery SoC is controlled in order to avoid overcharging or deep discharging. Finally, in case of a solid short-circuit within the microgrid, the battery undertakes to feed the fault with a high current and clear it. The proposed methodology is confirmed by detailed simulation results representing a microgrid in a Greek island. The microgrid contains a battery as an energy storage and is mainly fed by PVs and WGs.

Open Access This article is distributed under the terms of the Creative Commons Attribution 4.0 International License (http:// creativecommons.org/licenses/by/4.0/), which permits unrestricted use, distribution, and reproduction in any medium, provided you give appropriate credit to the original author(s) and the source, provide a link to the Creative Commons license, and indicate if changes were made.

\section{References}

[1] Ravindra K, Kannan B, Ramappa N (2014) Microgrids: a valuebased paradigm: The need for the redefinition of microgrids. IEEE Electrif Mag 2(1):20-29

[2] Nikkhajoei H, Lasseter RH (2009) Distributed generation interface to the CERTS microgrid. IEEE Trans Power Deliv 24(3): 1598-1608

[3] Koohi-Kamali S, Tyagi VV, Rahim NA et al (2013) Emergence of energy storage technologies as the solution for reliable operation of smart power systems: a review. Renew Sustain Energy Rev 25:135-165

[4] Kim JY, Jeon JH, Kim SK et al (2010) Cooperative control strategy of energy storage system and microsources for stabilizing the microgrid during islanded operation. IEEE Trans Power Electron 25(12):3037-3048

[5] Tan XG, Li QM, Wang H (2013) Advances and trends of energy storage technology in microgrid. Int J Electr Power Energy Syst 44(1):179-191

[6] Ricalde LJ, Ordonez E, Gamez M et al (2011) Design of a smart grid management system with renewable energy generation. In: Proceedings of the 2011 IEEE symposium on computational intelligence applications in smart grid (CIASG'11), Paris, France, 11-15 Apr 2011, 4 pp

[7] Giraud F, Salameh ZM (2001) Steady-state performance of a grid-connected rooftop hybrid wind-photovoltaic power system with battery storage. IEEE Trans Energy Convert 16(1):1-7
[8] EN 50160 (2004) Voltage characteristics of electricity supplied by public distribution system

[9] Olivares DE, Mehrizi-Sani A, Etemadi AH et al (2014) Trends in microgrid control. IEEE Trans Smart Grid 5(4):1905-1919

[10] Vandoorn TL, Vasquez JC, de Kooning J et al (2013) Microgrids: hierarchicalgy control and an overview of the control and reserve management strategies. IEEE Ind Electron Mag $7(4): 42-55$

[11] Cady ST, Dominguez-Garcia AD, Hadjicostis CN (2015) A distributed generation control architecture for islanded AC microgrids. IEEE Trans Control Syst Technol 23(5):1717-1735

[12] Liu W, Gu W, Sheng WX et al (2014) Decentralized multi-agent system-based cooperative frequency control for autonomous microgrids with communication constraints. IEEE Trans Sustain Energy 5(2):446-456

[13] Serban E, Serban H (2010) A control strategy for a distributed power generation microgrid application with voltage- and current-controlled source converter. IEEE Trans Power Electron 25(12):2981-2992

[14] Serban I, Marinescu C (2014) Control strategy of three-phase battery energy storage systems for frequency support in microgrids and with uninterrupted supply of local loads. IEEE Trans Power Electron 29(9):5010-5020

[15] Wu D, Tang F, Dragicevic T et al (2014) Autonomous active power control for islanded AC microgrids with photovoltaic generation and energy storage system. IEEE Trans Energy Convert 29(4):882-892

[16] Wu D, Tang F, Dragicevic T et al (2013) Coordinated primary and secondary control with frequency-bus-signaling for distributed generation and storage in islanded microgrids. In: Proceedings of the 39th annual conference of the IEEE Industrial Electronics Society (IECON'13), Vienna, Austria, 10-13 Nov 2013, pp 7140-7145

[17] de Matos JG, de Silva FSF, Ribeiro LA (2015) Power control in $\mathrm{AC}$ isolated microgrids with renewable energy sources and energy storage systems. IEEE Trans Ind Electron 62(6):3490-3498

[18] Fregosi D, Bhattacharya S, Atcitty S (2011) Empirical battery model characterizing a utility-scale carbon-enhanced VRLA Battery. In: Proceedings of the 2011 IEEE energy conversion congress and exposition (ECCE'11), Phoenix, AZ, USA, 17-22 Sept 2011, pp 3541-3548

[19] Triumph HP: valve regulated lead acid battery. HBL Power Systems Ltd, Hyderabad, India

[20] Rocabert J, Luna JA, Blaabjerg F et al (2012) Control of power converters in AC microgrids. IEEE Trans Power Electron 27(11):4734-4749

[21] Papaioannou IT, Alexiadis MC, Demoulias CS et al (2011) Modeling and field measurements of photovoltaic units connected to LV grid. Study of penetration scenarios. IEEE Trans Power Deliv 26(2):979-987

[22] Oureilidis KO, Demoulias CS (2014) An enhanced role for an energy storage system in a microgrid with converter-interfaced sources. J Eng. doi:10.1049/joe.2014.0281

[23] ABB Oil Distribution Transformer Catalogue (2001) Distribution transformers. ABB, Zurich, Switzerland. http://www.abb. com

Konstantinos O. OUREILIDIS received the Dipl. and Ph.D. degrees in electrical engineering from the Aristotle University of Thessaloniki, Thessaloniki, Greece, in 2008 and 2015, respectively. Currently, he is a researcher in the Electrical Machines Laboratory, Department of Electrical and Computer Engineering, Aristotle 
University of Thessaloniki. His research interests include power electronics, distributed generation and renewable energy sources.

Emmanouil A. BAKIRTZIS received the Dipl. Eng. Degree from the Department of Electrical and Computer Engineering, Aristotle University of Thessaloniki, Greece, in 2010, where he is currently pursuing the Ph.D. degree. His research interests include power system operation, analysis and control under high RES penetration.
Charis S. DEMOULIAS received the Dipl. and Ph.D. degrees in electrical engineering from the Aristotle University of Thessaloniki, Thessaloniki, Greece, in 1984 and 1991, respectively. Currently, he is Assistant Professor with the Electrical Machines Laboratory, Department of Electrical and Computer Engineering, Aristotle University of Thessaloniki. His research interests include power electronics, harmonics, electric motion systems, and renewable energy sources. 